Sustainability 2010, 2, 2024-2043; doi:10.3390/su2072024

Article

\title{
Delineation of Suitable Cropland Areas Using a GIS Based Multi-Criteria Evaluation Approach in the Tam Dao National Park Region, Vietnam
}

\section{Duong Dang Khoi * and Yuji Murayama}

Division of Spatial Information Science, Graduate School of Life and Environmental Sciences, University of Tsukuba,1-1-1 Tennodai, Tsukuba, Ibaraki 305-8572, Japan;

E-Mail: mura1@sakura.cc.tsukuba.ac.jp

* Author to whom correspondence should be addressed; E-Mail: khoi_tn@yahoo.com;

Tel.: +81-29-853-5694; Fax: +81-29-853-4211.

Received: 30 May 2010; in revised form: 22 June 2010 / Accepted: 29 June 2010 /

Published: 7 July 2010

\begin{abstract}
Land degradation is recognized as one of the major threats to the buffer zones of protected areas (PAs) in Vietnam. In particular, the expansion of land degradation into the PAs is exerting pressure on biodiversity conservation efforts. This degradation is partially the result of mismanagement: the utilization of the land is often unmatched with the inherent suitability of the land. Identification of the spatial distribution of suitable areas for cropland is essential for sustainable land-use recommendation. This paper aims to delineate the areas suitable for cropland in the Tam Dao National Park (TDNP) region using a GIS-based multi-criteria evaluation of biophysical factors and Landsat $\mathrm{ETM}^{+}$imagery. GIS is used to generate the factors, while MCE is used to aggregate them into a land suitability index. The results indicate the location and extent of crop farming areas at different suitability levels, i.e., most suitable (28.10\%), moderately suitable (23.96\%), marginally suitable (28.77\%), and least suitable (19.17\%). The current cropland covers $46.5 \%$ of the study area, while most and moderately suitable areas are estimated to be $52.06 \%$ of the territory. The results can be used to identify priority areas for crop farming and sustainable land-use management. The GIS-MCE approach provides an effective assessment tool for land-use managers working in protected areas of Vietnam.
\end{abstract}

Keywords: land suitability analysis; multi-criteria evaluation; analytical hierarchy process; fuzzy set; Vietnam 


\section{Introduction}

Protected areas (PAs) have become a universally adopted way of conserving biodiversity for a wide range of human values. Globally, $11.2 \%$ of the total forest area has been designated for the conservation of biological diversity [1]. A PA is defined as "an area of land and/or sea especially dedicated to the protection of biological diversity, and of natural and associated cultural resources, and managed through legal or other effective means” [2]. Though PAs are designed for biodiversity conservation goals, they are also important to the livelihoods of local communities, particularly of indigenous people who depend on the resources available in the PAs for their survival $[3,4]$. In Vietnam, PAs are strongly affected by nearby rural communities because the people's livelihoods often heavily depend on land and forest resources from PAs [5,6]. Driven by population pressure in the PAs' buffer zones, increasing demands of food, timber, and non-timber products have resulted in agricultural expansion into PAs [6]. To control agricultural expansion into PAs and ensure sustainable uses of land in the buffer zones, there is a great need to locate agricultural production activities to suitable locations to avoid ecological consequences. PA managers are often requested to identify the spatial distribution of suitable areas for cropland in the buffer zone. One way to achieve this identification is to employ a land suitability assessment (LSA) tool.

An LSA is a prerequisite for determining and locating future land uses [7,8]. It is the process of determining the fitness of a given parcel of land for a defined use [9]. An LSA involves the selection of the biophysical or socio-economic factors, or both, of an area; the combination of the selected factors with the decision-maker's preferences allows one to create a composite suitability index [10]. Therefore, it can be conceptualized as a multiple criteria decision-making problem [11]. Boolean overlay and modeling approaches, such as neural networks and evolutionary algorithms, are recently developed methods for making LSAs in the GIS environment. However, these approaches lack a well-defined mechanism for incorporating the decision-maker's preferences into the GIS procedures [12]. This disadvantage can be solved by integrating GIS and multi-criteria evaluation (MCE) methods. The MCE is an effective tool for multiple criteria decision-making issues [12]. The purpose of the MCE is to investigate a number of choice possibilities in light of multiple criteria and multiple objectives [13]. Integration of the MCE and GIS (GIS-MCE) can help land-use planners and managers to improve decision-making processes [14]. GIS enables the computation of assessment factors, while MCE aggregates them into a land suitability index.

This study aims to delineate the areas suitable for cropland through a GIS-based MCE approach using biophysical factors and the 2007 Landsat ETM ${ }^{+}$imagery for the Tam Dao National Park (TDNP) region, Vietnam. We believe that biodiversity conservation efforts can be improved if priority areas for crop farming and sustainable land uses in the buffer zone are modified based on a comprehensive land evaluation. We selected the TDNP region as a case study because this region is the last remaining primary forest nearby Hanoi, the capital of Vietnam. It contains a rich biodiversity, but several species are known to be threatened by habitat destruction due to agricultural expansion [15]. 


\section{Methods}

\subsection{Study Area}

The TDNP region is one of the most important protected areas in Vietnam. This region is situated in the northern part of Vietnam (Figure 1). It is considered to be one of the best and largest rainforest habitat examples in Vietnam. It is endowed with a diversity of insects, butterflies, birds, medical plants, and rare animals [16]. A recent biological survey identified 1,436 plant species and 1,141 animal species [15].

Figure 1. Location of the Tam Dao National Park region, Vietnam.

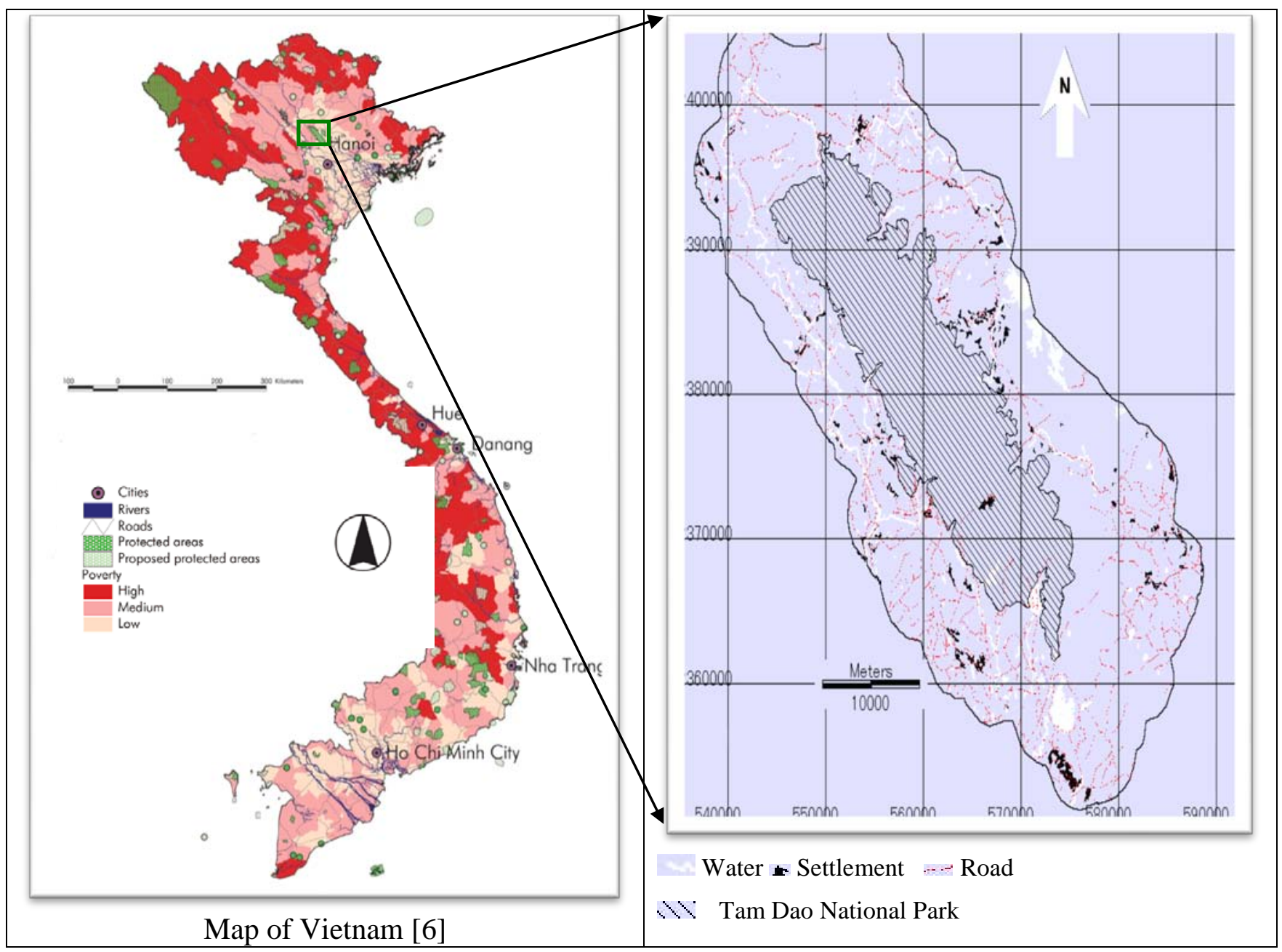

The region is characterized by a tropical monsoon climate with a mean annual rainfall of around 2,600 mm, and most of the rainfall occurs from April to October. The terrain of the area is mostly undulating with steep pediments, and the elevation ranges from 100 to 1,580 meters above mean sea level. The total study area spreads over 141,328 hectares; the area includes the TDNP (35,000 ha) and the buffer zone. The current land uses over the entire study area are primary forest, secondary forest, rain-fed agriculture, paddy rice, settlement, and water. Deforestation due to illegal logging and agricultural expansion has been causing serious land degradation (Figure 2) because most of the 200,000 people residing in the buffer zone of the TDNP generate their incomes from small-scale 
farming. Aside from agricultural production, few economic activities exist in the area [17]. Currently, the main challenge for the buffer zone is to ensure food production for the growing population while supporting biodiversity conservation goals. The cropland was chosen for this investigation because the expansion of cropland influences the sustainability of the TDNP.

Figure 2. Forest logging for agricultural expansion in the buffer zone of the TDNP (photo by author, 2009).

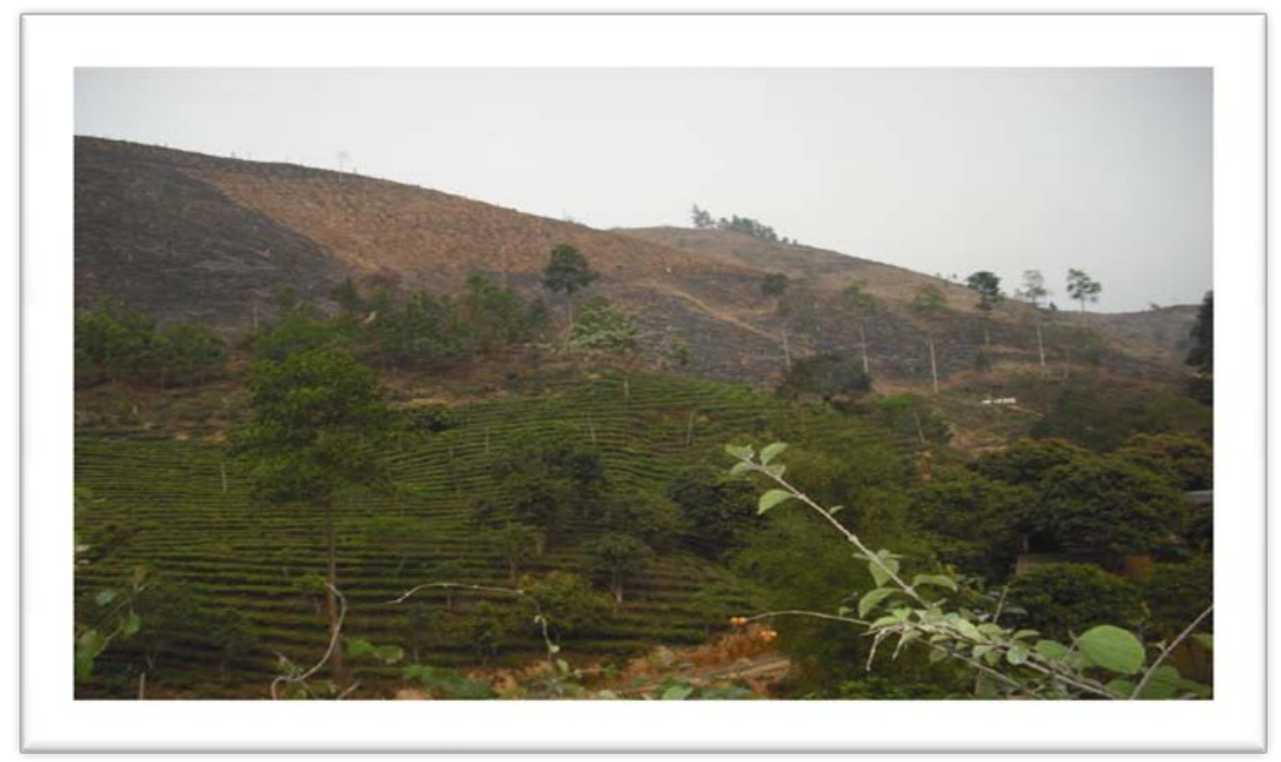

\subsection{Input Data and Landsat Image Processing}

The input data used for this study was based on the selected evaluation factors discussed in the next part. They include a topographical map, soil map, water resource map, road network map, and park boundary map (Table 1). These data were used for delineating areas suitable for cropland. Landsat satellite images were used to derive the current land-use map to analyze spatial matching between the current land uses and suitability patterns.

Once the databases were collected, thematic maps were developed for each factor. A digital elevation model (DEM) was constructed using a contour map with a scale of 1:50,000 and an interval of 20 meters. The slope factor was derived from this DEM. Soil texture, soil depth, soil organic matter and soil $\mathrm{pH}$ factor maps were extracted from the digitized soil map with a scale of 1:100,000. The distances to water, roads, and the park boundary were generated from the water, road network, and park boundary maps, respectively. The resolution of all raster factor maps was set at $30 \mathrm{~m} \times 30 \mathrm{~m}$.

The Landsat satellite images acquired in 2007 were used to derive the recent land-use map. Six bands (bands 1-5 and 7) were processed to derive the land-use map. The image was rectified to a common UTM/WGS84 coordinate system that is based on the topographic map. The clusters of pixels representing various land-use types were identified as training sites that are based on unsupervised classification, an existing land-use map, and the knowledge of the authors on the relative locations of land-use types. After all training sites were identified and digitized by the on-screen method, the class signatures were generated. A maximum likelihood method was used to classify these images into the land-use map. The accuracy of the classified map was investigated. A stratified random sampling 
design was employed to identify 270 locations (pixels) for field data collection. During the field trip, GPS equipment was used to trace geographical data, and a digital camera was used to record the views of the locations for lab analysis.

Table 1. List of databases used in this research.

\begin{tabular}{llll}
\hline Data types & Year & Scale/resolution & Sources \\
\hline Topographical map & 1972 & $1: 50,000$ & TDNP Management Office \\
Soil map & 2005 & $1: 100,000$ & $\begin{array}{l}\text { National Institute for Agricultural } \\
\text { Planning, Ministry of Agriculture and } \\
\end{array}$ \\
& & & $\begin{array}{l}\text { Rural Development and TDNP } \\
\text { Management Office }\end{array}$ \\
& & & TDNP Management Office \\
Road network & 2007 & - & TDNP Management Office \\
Water bodies & 2007 & - & TDNP Management Office \\
Park boundary & 2007 & - & University of Maryland \\
Landsat images & 2007 & 28.5 meters & TDNP region \\
Field survey & 2009.3 & - & \\
\hline
\end{tabular}

\subsection{Multi-Criteria Evaluation}

The GIS-MCE procedure for the cropland suitability assessment in the TDNP region included several stages that are framed in Figure 3. The determination of the relevant factors was the starting step in the assessment and was followed by standardizing the factors, weighting the factors, combining the factors with their weights, and finally spatially matching between the suitability map and the current land-use map. The procedures and algorithms available in IDRISI Taiga [18] were employed to implement the assessment.

Initially, the factors were selected based on their relevance to the suitability of cropland and the availability of databases. The selection of factors is a technical process that is based on expert knowledge or empirical research. We selected 12 experts to be involved in the assessment, who were between 30 and 50 years of age. They participated in selecting the factors, identifying the suitable ranges of the factors, and evaluating the weights of the factors. They include five agronomy experts, five soil experts, and two forestry experts. Eleven of the experts have bachelor's degrees, and one expert has a master's degree. These experts have worked at least five years at the office of the TDNP and have worked for the district department of agriculture and rural development in the region. After discussion with the experts during the field survey period, nine factors (slope, elevation, distance to water, soil organic matter, soil depth, soil $\mathrm{pH}$, soil texture, distance to roads, and distance to the TDNP boundary) were identified to be most relevant for the suitability assessment of crop growing areas in the region. The elevation, slope (terrain), and the distance to water are important determinants of cropland suitability because the terrain often has a relationship with soil fertility as well as with the vulnerability of soil to degradation. The slope relates to the retention and movement of soil particles and the rates of runoff and soil erosion; therefore, it closely regulates the soil quality condition. The soil characteristics (soil organic matter, soil depth, soil $\mathrm{pH}$, and soil texture) represent the soil nutrients and water availability for crop growth. The distance to roads is important for crop production because it relates to the transportation cost of input and output items. The distance to the park is defined as the 
suitability that is monotonically reduced in areas closer to the park boundary. This variable is included in the land suitability assessment because cultivation areas closer to the park may alter more seriously the environmental quality of the protected area.

Figure 3. Flowchart of the land suitability assessment for cropland (AHP: Analytical Hierarchy Process, WLC: Weighted Linear Combination).

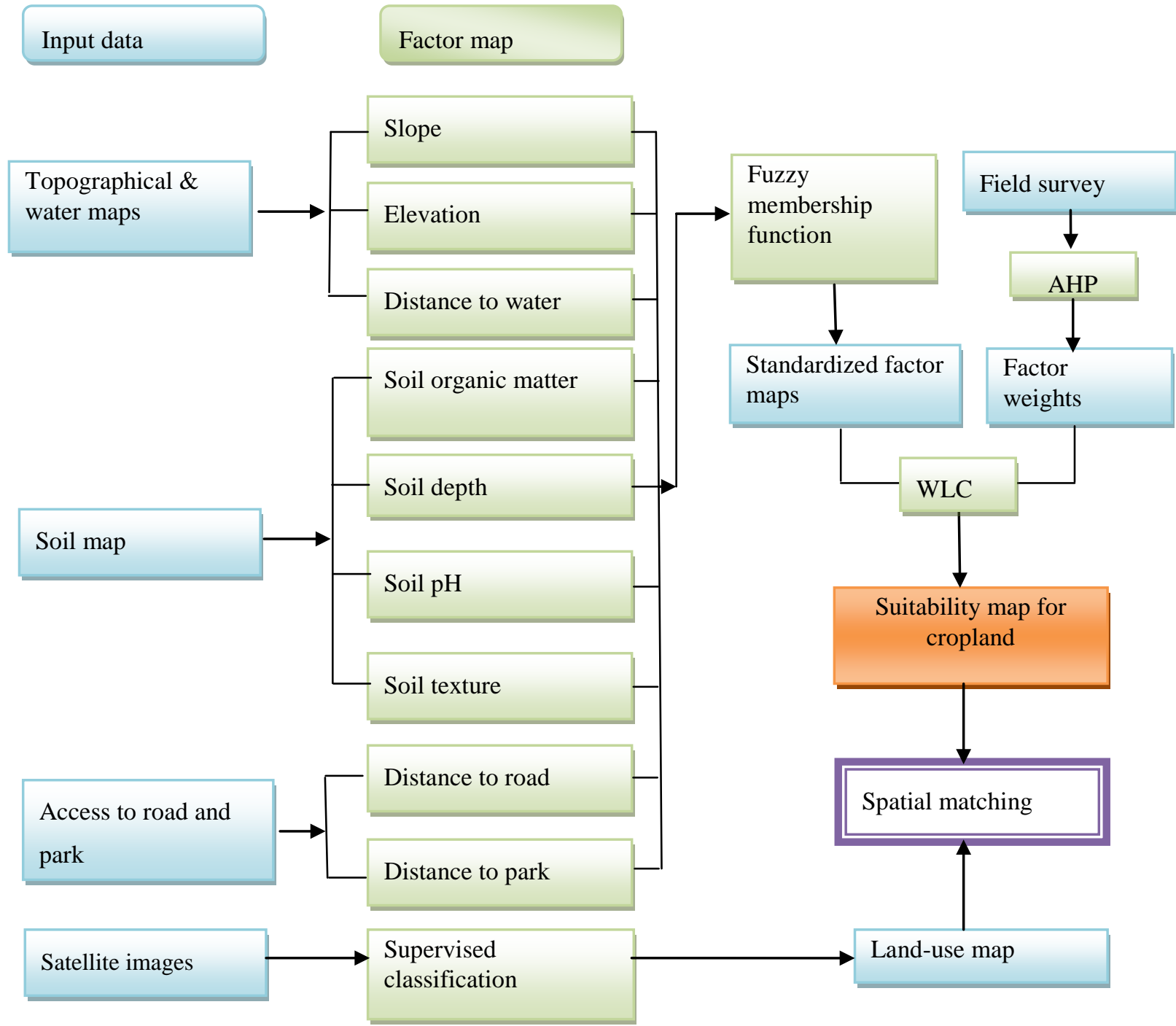

As the factor maps were measured in different original scales, these maps have to be standardized to a uniform suitability rating scale. The MCE method used requires that all factors must be standardized. The standardization transforms the disparate measurement units of the factor maps into comparable suitability values [18]. The fuzzy membership function (FMF) approach was applied to standardize the factors. This method provides a useful means of dealing with uncertainty that results from the imprecise boundaries between suitability classes [19,20]. An FMF is characterized by a fuzzy membership grade that ranges from 0 (non-membership) to 1 (complete membership) [18]. For each factor, it was defined that the least suitable level is 0 , and the most suitable level is 1 . Several FMFs can be used to standardize the factors. The sigmoidal fuzzy membership function is one of the most widely used fuzzy membership functions in land evaluation [18]. In this study, sigmoidal monotonically decreasing fuzzy membership function (SMDFM) and sigmoidal monotonically 
increasing fuzzy membership function (SMIFM) were employed. Higher values in elevation, slope, distance to water, and distance to roads would indicate continuously decreasing suitability; therefore, the SMDFM was used to standardize these factors. On the other hand, higher values in the factors of soil organic matter, soil depth, soil $\mathrm{pH}$, and distance to the park boundary would show continuously increasing suitability; thus, the SMIFM was used to standardize these factors. Suitable values for soil texture were assigned according to each textural class. The detailed descriptions of sigmoidal FMFs can be found in [18]. To apply the FMF, the suitable ranges of the factors that define the lowest and greatest suitability levels were determined based on the experts, and somewhat similar studies had been successfully conducted for cropland suitability assessment [21-23] (Table 2). Suitable ranges for the factors were identified according to the opinions of the experts, and they were also verified by our field visits. Figure 4 shows the results of the standardized factor maps. A standardized factor map consists of pixels with continuous scores varying from 0 to 1 . A higher pixel score indicates a higher suitability level for that pixel.

Table 2. Suitable ranges used for fuzzy membership function.

\begin{tabular}{|c|c|c|c|}
\hline Factor & $\begin{array}{l}\text { Non-membership } \\
\text { (unsuitable) }\end{array}$ & $\begin{array}{l}\text { Membership grade } \\
\text { (suitable range) }\end{array}$ & References \\
\hline Slope (degree) & $>15$ & $1-15$ & $\begin{array}{l}\text { TDNP agronomy experts } \\
\text { Slope from } 1^{\circ} \text { to } 25^{\circ}[21], 1^{\circ} \text { to } 15^{\circ}[22,23]\end{array}$ \\
\hline Elevation (m) & $>400$ & $1-400$ & $\begin{array}{l}\text { TDNP agronomy experts } \\
\text { Elevation from } 1 \text { to } 500 \mathrm{~m} \text { [22] }\end{array}$ \\
\hline Distance to water (m) & $>2,000$ & $100-2,000$ & TDNP agronomy experts \\
\hline Soil organic matter (\%) & $<0.5$ & $0.5-2.3$ & $\begin{array}{l}\text { TDNP agronomy experts } \\
\text { Less than } 1 \% \text { to } 3 \% \text { [22] }\end{array}$ \\
\hline Soil depth (cm) & $<20$ & $20-150$ & $\begin{array}{l}\text { TDNP agronomy experts } \\
\text { Soil depth range from } 10 \mathrm{~cm} \text { to } 60 \mathrm{~cm} \text { [22], } \\
15 \mathrm{~cm} \text { to more than } 30 \mathrm{~cm} \text { [23] } \\
\end{array}$ \\
\hline Soil pH & $<4.5$ and $>7.5$ & $4.5-6.9$ & $\begin{array}{l}\text { TDNP agronomy experts } \\
\mathrm{pH} \text { range from } 5 \text { to } 8 \text { [22] }\end{array}$ \\
\hline Soil texture (class) & - & $\begin{array}{l}\text { Sandy clay loam, } \\
\text { sandy loam, } \\
\text { silt loam, loam }\end{array}$ & $\begin{array}{l}\text { TDNP agronomy experts } \\
\text { Medium loam is most suitable, light and heavy loam } \\
\text { is moderately suitable, sandy loam and medium clay } \\
\text { is marginally suitable }[22,23]\end{array}$ \\
\hline Distance to roads (m) & $>4,000$ & $100-4,000$ & TDNP agronomy experts \\
\hline $\begin{array}{l}\text { Distance to the park } \\
\text { boundary (m) }\end{array}$ & $<500$ & $500-11,277$ & TDNP agronomy experts \\
\hline
\end{tabular}

The evaluation of suitability involves many factors, and each should be weighed according to its relative importance for the growth conditions of crops. The weight of each factor was estimated from a pairwise comparison matrix (PWCM) constructed according to a pairwise comparison method (PCM) (Table 3). The PCM developed by references [24,25], in the context of a decision-making process known as the analytical hierarchy process, is the most commonly used method [26]. In the PWCM, a pairwise comparison is a rating of the relative importance of the two factors regarding the suitability of the cropland. The PWCM method uses a scale with values from 9 to 1/9 to rate the relative importance 
of the two factors. A rating of 9 indicates that in relation to the column factor, the row factor is more important. On the other hand, a rating of 1/9 indicates that relative to the column factor, the row factor is less important. In cases where the column and row factors are equally important, they have a rating value of 1 .

Table 3. The pairwise comparison matrix for evaluating the relative importance of the factors for each land-use requirement (the number indicates the rating of the row factor relative to the column factor).

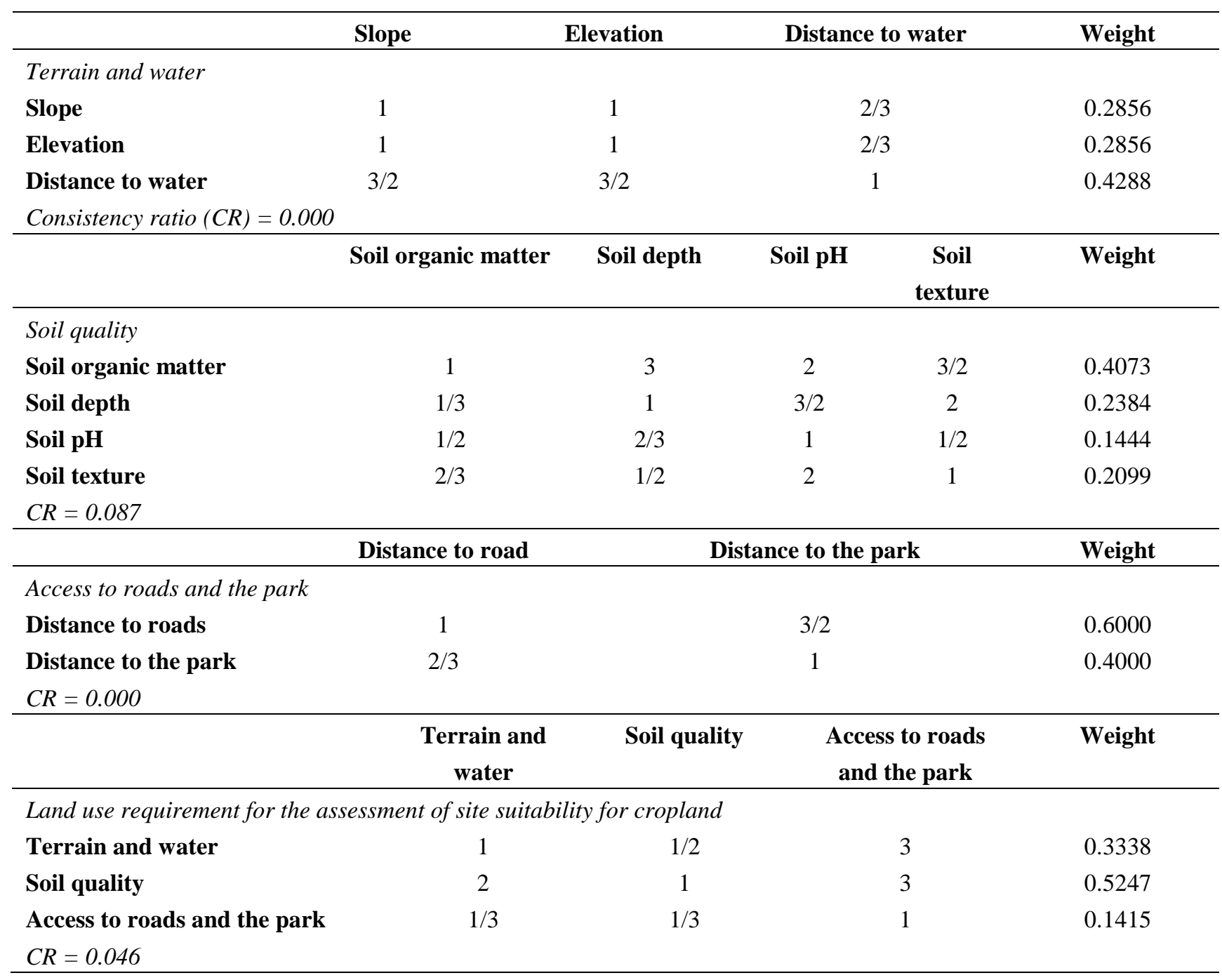

In determining the ratings, 12 experts, as previously described, worked as a group to determine the ratings of the factors. To reach agreement in rating the relative importance of the factors, a majority rule was applied. This means that each rating in the pairwise comparison matrix was compared and decided based on the agreement of the majority of experts. In the context of the workshop for determining the relative importance of the factors, a description of the evaluation purpose, an identification of the set of relevant factors, and an explanation of a PWCM and completion procedure were carried out. After discussion and careful examination of the set of factors, the group made all the pairwise comparisons for the set of factors. The PWCMs developed are shown in Table 3. The weights of the factors were then calculated from these PWCMs. The consistency ratios (CRs) of 0.000 to 0.087 
for the table were within the acceptable level [24,25]. According to references [24,25], the calculated CR must be less than 0.1, which is the acceptability cut-off. This means that if the computed CR is less than 0.1, the calculated weights of the factors are consistent. If the calculated CR is more than 0.1, the pairwise comparison matrix needs to be re-evaluated, and the weights of the factors also need to be re-calculated accordingly. An example of spreadsheet calculations for the CR of overall site suitability factors for cropland is shown in Table 4. The points (a) and (b) show the calculation of the factor weights. The parts (c), (d), and (e) show the calculations of the CR.

Table 4. Example of spreadsheet calculations for the consistency ratio of site suitability for cropland.

\begin{tabular}{|c|c|c|c|c|c|c|c|c|c|c|c|c|c|c|}
\hline & \multicolumn{3}{|c|}{ Values } & \multicolumn{3}{|c|}{ Decimal } & \multicolumn{3}{|c|}{ Normalization } & \multirow[t]{2}{*}{ Weight } & \multirow[t]{2}{*}{$\lambda$} & \multirow[t]{2}{*}{ CI } & \multirow[t]{2}{*}{$\mathbf{R I}$} & \multirow[t]{2}{*}{ CR } \\
\hline & TW & SQ & $\mathrm{RP}$ & TW & SQ & $\mathrm{RP}$ & TW & SQ & $\mathrm{RP}$ & & & & & \\
\hline TW & 1 & $1 / 2$ & 3 & 1.00 & 0.50 & 3.00 & 0.30 & 0.27 & 0.43 & 0.3338 & & & & \\
\hline SQ & 2 & 1 & 3 & 2.00 & 1.00 & 3.00 & 0.60 & 0.55 & 0.43 & 0.5247 & 3.0538 & 0.0269 & 0.58 & 0.0464 \\
\hline $\mathrm{RP}$ & $1 / 3$ & $1 / 3$ & 1 & 0.33 & 0.33 & 1.00 & 0.10 & 0.18 & 0.14 & 0.1415 & & & & \\
\hline Sum & & & & 3.33 & 1.83 & 7.00 & & & & 1.0000 & & & & \\
\hline
\end{tabular}

$\mathrm{TW}=$ terrain and water, $\mathrm{SQ}=$ soil quality, $\mathrm{RP}=$ access to roads and the park.

(a) Sum the numbers in each column of the values matrix; divide each number in the decimal matrix by the column sum; the resulting matrix is the normalization matrix.

(b) Average the numbers in each row of the normalization matrix; the average value is the weight.

(c) Compute lambda ( $\lambda$ ) by the following steps [14]: (1) determine the weighted sum vector by multiplying the weight of the TW, the weight of the SQ, and the weight of the WP times the first column, the second column, and the third column of the values matrix, respectively, and finally, sum these values over the rows; (2) determine the consistency vector by dividing the weighted sum vector by the factor weights as per the following.

\begin{tabular}{ll}
\hline \multicolumn{1}{c}{ Step 1 } & \multicolumn{1}{c}{ Step 2 } \\
\hline$(1)(0.3338)+(0.5)(0.5247)+(3)(0.1415)=1.0208$ & $1.0208 / 0.3338=3.05837$ \\
$(2)(0.3338)+(1)(0.5247)+(3)(0.1415)=1.6169$ & $1.6169 / 0.5247=3.08168$ \\
$(0.3333)(0.3338)+(0.3333)(0.5247)+(1)(0.1415)=0.4277$ & $0.4277 / 0.1416=3.02140$ \\
\hline
\end{tabular}

Then, $\lambda=(3.05837+3.08168+3.02140) / 3=3.0538$

(d) The Consistency Index (CI) is $(\lambda-n) /(n-1),(3.0538-3) / 2=0.0269$

(e) The Consistency Ratio (CR) is CI/RI, where RI is the Random Consistency Index. For n = 3, RI = 0.58 [24]. $\mathrm{CR}=0.0269 / 0.58=0.0464$.

After the standardized factor maps and the weights of the factors were constructed and generated, the weighted linear combination (WLC) was used to combine the standardized factors and their corresponding weights to obtain an overall suitability map for the cropland [26]. All of the factors were combined as Grid result $=\Sigma\left(\right.$ Grid $_{\mathrm{i}} \times$ Weight $\left._{\mathrm{i}}\right)$. Grid $\mathrm{i}_{\mathrm{i}}$ is the factor $\mathrm{i}$, and Weight $\mathrm{w}_{\mathrm{i}}$ is the relative weight of factor i. Specifically, the three factors of terrain and water, the four factors of soil quality, and the two factors of access to roads and the park were calculated by equations (1), (2), and (3), and then they were all overlaid to produce the overall cropland suitability map according to Equation (4). Finally, the recent land-use map and the suitability map were overlaid to analyze the spatial matching. A simple overlay technique was used between the land-use map and the suitability map, and then the statistics of the suitability classes for each land use were calculated. 
Terrain and water grid $=$

$$
\begin{gathered}
\text { Grid }_{\text {slope }} \times 0.2856+\text { Grid }_{\text {elevation }} \times 0.2856+\text { Grid }_{\text {distance to water }} \times 0.4288 \\
\text { Soil quality grid }= \\
\text { Grid }_{\text {soil organic matter }} \times 0.4073+\text { Grid }_{\text {soil depth }} \times 0.2384+\text { Grid }_{\text {soil pH }} \times 0.1444 \\
+ \text { Grid }_{\text {soil texture }} \times 0.2099
\end{gathered}
$$

Access to roads and the park grid $=$

$$
\text { Grid }_{\text {distance to roads }} \times 0.6+\text { Grid }_{\text {distance to the park }} \times 0.4
$$

Overall suitability grid $=$

$$
\begin{aligned}
& \text { Grid }_{\text {terrain and water }} \times 0.3338+\text { Grid }_{\text {soil quality }} \times 0.5247+ \\
& \text { Grid }_{\text {access to roads and the park }} \times 0.1415
\end{aligned}
$$

Figure 4. Standardized factor maps (the legend is the same as the elevation map for all factor maps).

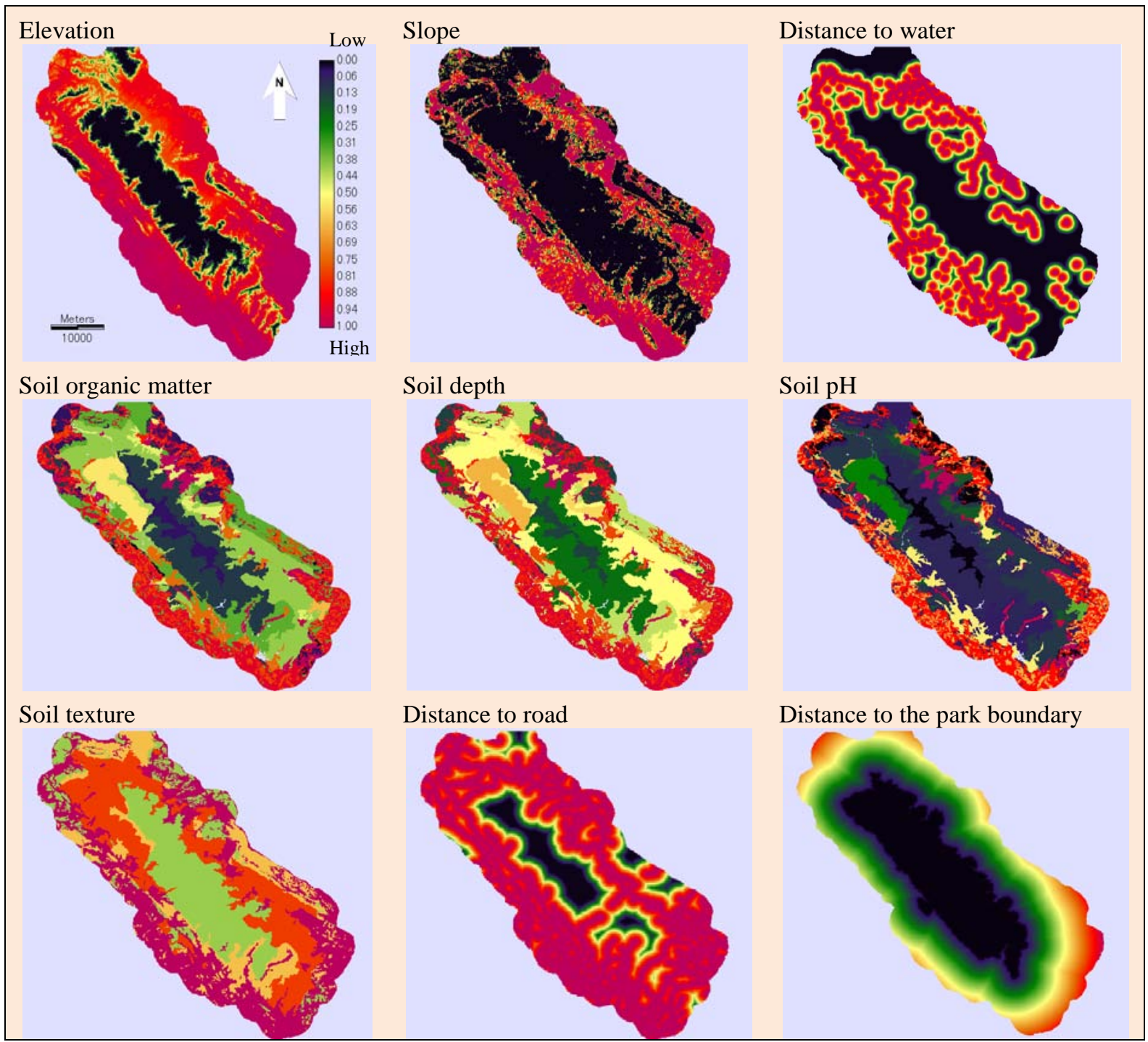




\section{Results}

Figure 5 shows the suitability map for the cropland in the TDNP region. The map contains pixels with varying degrees of suitability from 0 to 1 . A higher pixel score shows a higher suitability level. The map was re-classified, for easier representation, into four classes based on the structure of the FAO suitability classification [27]: the most suitable (0.75-0.96), the moderately suitable (0.5-0.75), the marginally suitable $(0.25-0.5)$, and the least suitable $(0-0.25)$. The most suitable is the land with minor limitations that do not significantly affect crop farming. The moderately suitable is the land with limitations that, in aggregate, are moderately limiting to crop farming. The marginally suitable is the land that has limitations, which, in aggregate, are severely damaging to crop farming. The least suitable is the land with limitations that, in aggregate, are very severely damaging to crop farming. The extent of each class is summarized in Table 5 . The result indicates that $28.10 \%$ of the total study area was found to be the most suitable class. These most suitable areas are mainly characterized by flatness, a nearness to water, and deep soil depth. The moderately suitable class was found to be $23.96 \%$ of the territory. Both the most and moderately suitable classes were $52.06 \%$ of the total area, whereas the existing cropland area was $46.5 \%$. This result highlights that the most and the moderately suitable areas have been used for the cropland in the region. The least suitable and marginally suitable classes were $19.17 \%$ and $28.77 \%$, respectively. These areas are often located in areas with steepness, low soil depth, and less water access. If the farmers are forced to reclaim land for agriculture due to population pressures, the marginally suitable areas that are highly vulnerable to soil erosion may be the target areas of the future.

Table 5. Area of the cropland suitability classes.

\begin{tabular}{lcc}
\hline Suitability class & Area (ha) & Proportion (\%) \\
\hline Least suitable & 27,069 & 19.17 \\
Marginally suitable & 40,639 & 28.77 \\
Moderately suitable & 33,846 & 23.96 \\
Most suitable & 39,683 & 28.10 \\
\hline
\end{tabular}

Different factors play different importance levels for the site suitability of cropland. The result of evaluating the relative importance of factors shows that the soil quality (soil organic matter, soil depth, soil $\mathrm{pH}$, and soil texture) is the most important, followed by the terrain and water (slope, elevation, and distance to water) and access to roads and the park (distance to roads and distance to the park boundary). The soil quality with a weight of 0.5247 is determined to have a major impact on the overall suitability because it regulates the storage of soil nutrients and the water-holding capacity, which are necessary biophysical conditions for crop growth. The topographical and water factor, with a weight of 0.3338 , is the second contributor. The slope affects the retention and movement of water and soil particles, the rate of runoff, and accelerated soil erosion. These effects are closely linked to the soil quality conditions. Elevation relates to increased water-pumping costs for agricultural production. Water availability is very important for crop growing in the area. Natural lakes, ponds, streams, and rivers are major water providers for agricultural production in the area. Water resources in the region mostly depend on sources from the TDNP forest ecosystems. Therefore, there is a strong link between 
the conservation of native forest ecosystems and agricultural development in the region. The access to roads and the park plays a weaker role compared to the others. Road networks are significant for local communities by enhancing commercial agricultural activities and transportation. The distance to the park boundary affects the biodiversity conservation activity of the TDNP; therefore, it relates to the site suitability of cropland.

Figure 5. Land suitability map for cropland in the TDNP region.

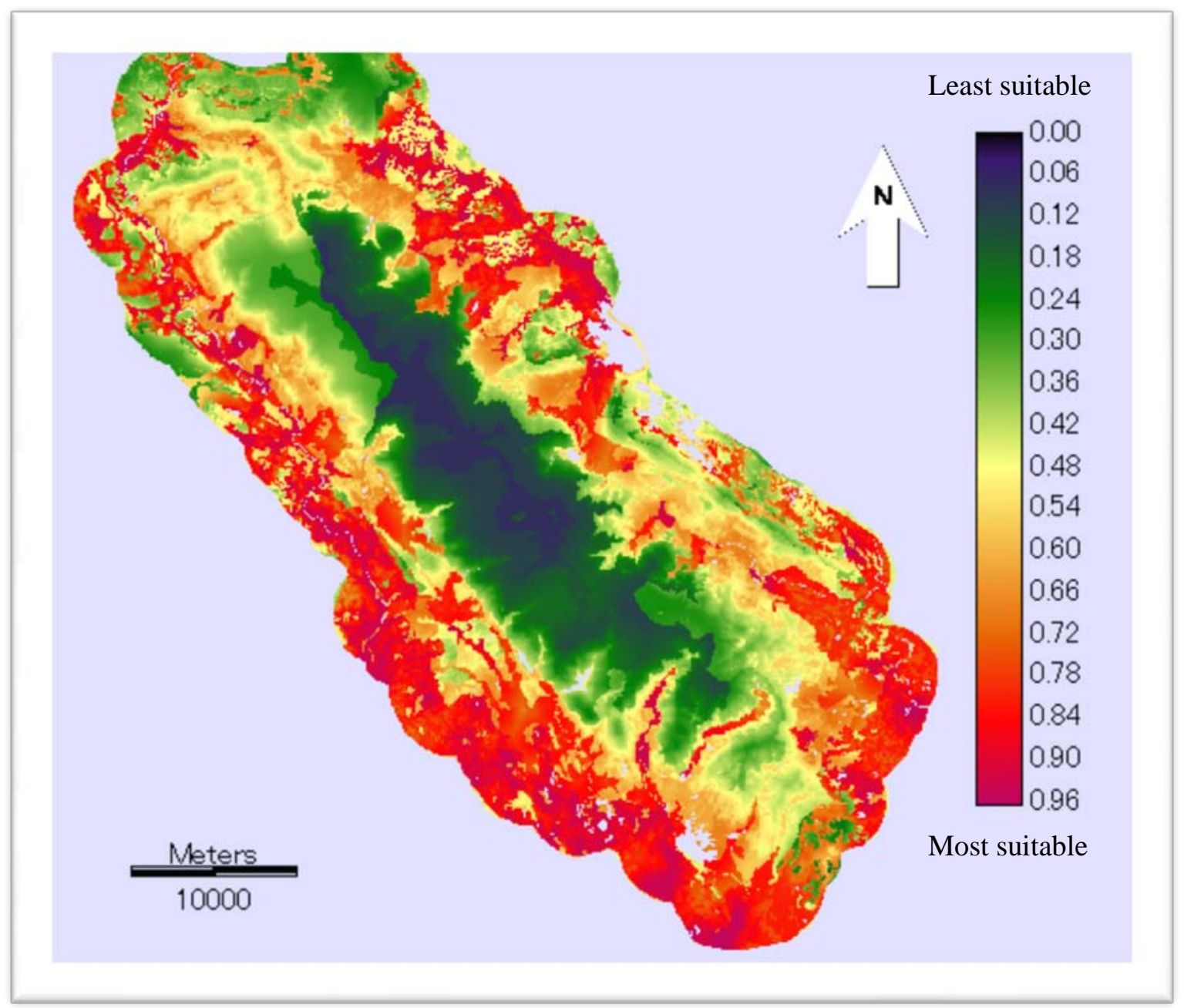

The spatial matching offered valuable information to identify whether the land was optimally utilized in the region. The result of overlaying the suitability map (Figure 6) with the land-use map of 2007 (Figure 7) is presented in Table 6. The accuracy of the land-use map based on Kappa statistics was $90.1 \%$. The land-use map indicates that the major land uses are primary forest (25,459 ha), secondary forest (44,018 ha), rain-fed agriculture (41,117 ha), paddy rice (24,567 ha), settlement (3,130 ha), and water (2,947 ha), which account for $18.03 \%, 31.17 \%, 29.11 \%, 17.39 \%, 2.22 \%$, and $2.09 \%$, respectively, of the total study area. The primary forest that is mainly dense and native vegetation is mainly located in the park. The secondary forest includes both forest plantations and shrubs. The rain-fed agriculture is characterized by a mixture of crops, mainly soybeans, peanuts, vegetables, and maize. The paddy field is used only for rice production. Settlement consists of small 
houses, front- and backyards, and home gardens. Water resources include a variety of natural lakes, ponds, streams, and rivers.

Figure 6. Map of the suitability zones.

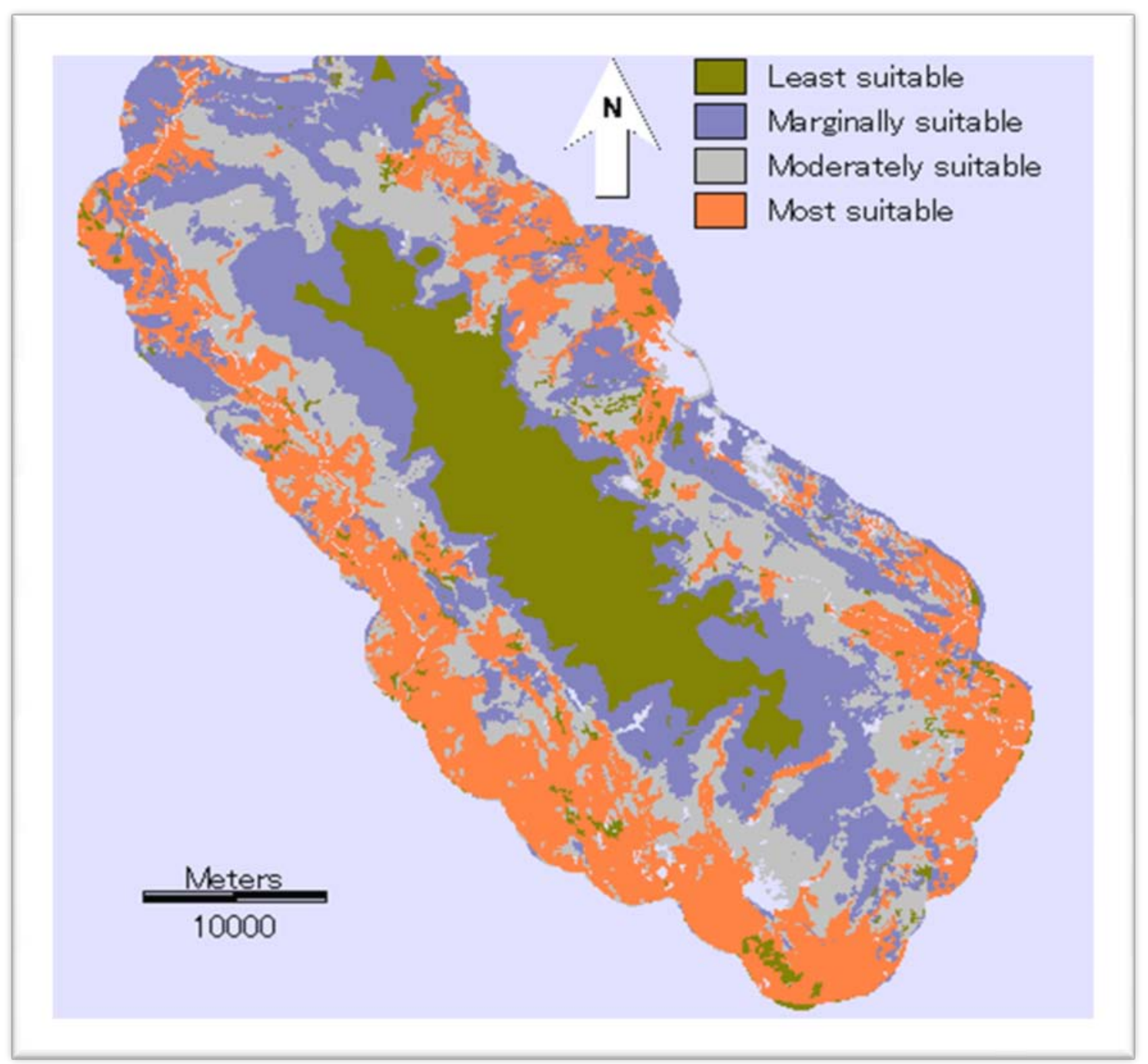

Table 6. The overlaying result between the suitability map and the land-use map of 2007.

\begin{tabular}{|c|c|c|c|c|c|c|c|c|c|}
\hline \multirow[t]{3}{*}{ Land-use type } & \multicolumn{9}{|c|}{ Level of suitability } \\
\hline & \multicolumn{2}{|c|}{ Most suitable } & \multicolumn{2}{|c|}{$\begin{array}{l}\text { Moderately } \\
\text { suitable }\end{array}$} & \multicolumn{2}{|c|}{$\begin{array}{c}\text { Marginally } \\
\text { suitable }\end{array}$} & \multicolumn{2}{|c|}{$\begin{array}{c}\text { Least } \\
\text { suitable }\end{array}$} & \multirow{2}{*}{$\begin{array}{c}\text { Total } \\
\text { land-use } \\
\text { ha }\end{array}$} \\
\hline & ha & $\%$ & ha & $\%$ & ha & $\%$ & ha & $\%$ & \\
\hline Primary forest & 8 & 0.02 & 42 & 0.12 & 6,072 & 14.94 & 19,337 & 71.44 & 25,459 \\
\hline Secondary forest & 1,339 & 3.37 & 11,359 & 33.56 & 29,006 & 71.37 & 2,314 & 8.55 & 44,018 \\
\hline Rain-fed agriculture & 19,039 & 47.98 & 16,738 & 49.45 & 5,099 & 12.55 & 241 & 0.89 & 41,117 \\
\hline Paddy rice & 18,748 & 47.24 & 5,394 & 15.94 & 251 & 0.62 & 174 & 0.64 & 24,567 \\
\hline Settlement & 549 & 1.38 & 313 & 0.92 & 212 & 0.52 & 2,056 & 7.60 & 3,130 \\
\hline Water & - & - & - & - & - & - & 2,947 & 10.89 & 2,947 \\
\hline Total suitable class & 39,683 & 100.00 & 33,846 & 100.00 & 40,640 & 100.00 & 27,069 & 100.00 & 141,238 \\
\hline
\end{tabular}


As expected, the most suitable and moderately suitable areas were found in the existing rain-fed agriculture and paddy fields. The result indicates that $95.22 \%$ of the most suitable class was distributed over the rain-fed agriculture and the paddy rice, while only $3.37 \%$ of the class was located in the secondary forest. With respect to the moderately suitable class, $83.01 \%$ of the class was found in the rain-fed agriculture and the secondary forest, whereas only $15.94 \%$ of the class was located in the paddy rice. For the marginally suitable class, $71.37 \%$ of the class was found in the secondary forest. This class was also found in the primary forest (14.94\%) and the rain-fed agriculture (12.55\%). Finally, the least suitable class was mainly stretched over the primary forest. The most and moderately suitable areas have already been utilized for paddy rice and rain-fed agricultural crops. Although some of the rain-fed agricultural areas may cause land degradation due to soil erosion, these utilized lands may not be easily changed towards more sustainable uses, such as agro-forest farming or fruit trees, in the future because of the growing population in the area.

Figure7. The land-use map derived from the Landsat images of 2007.

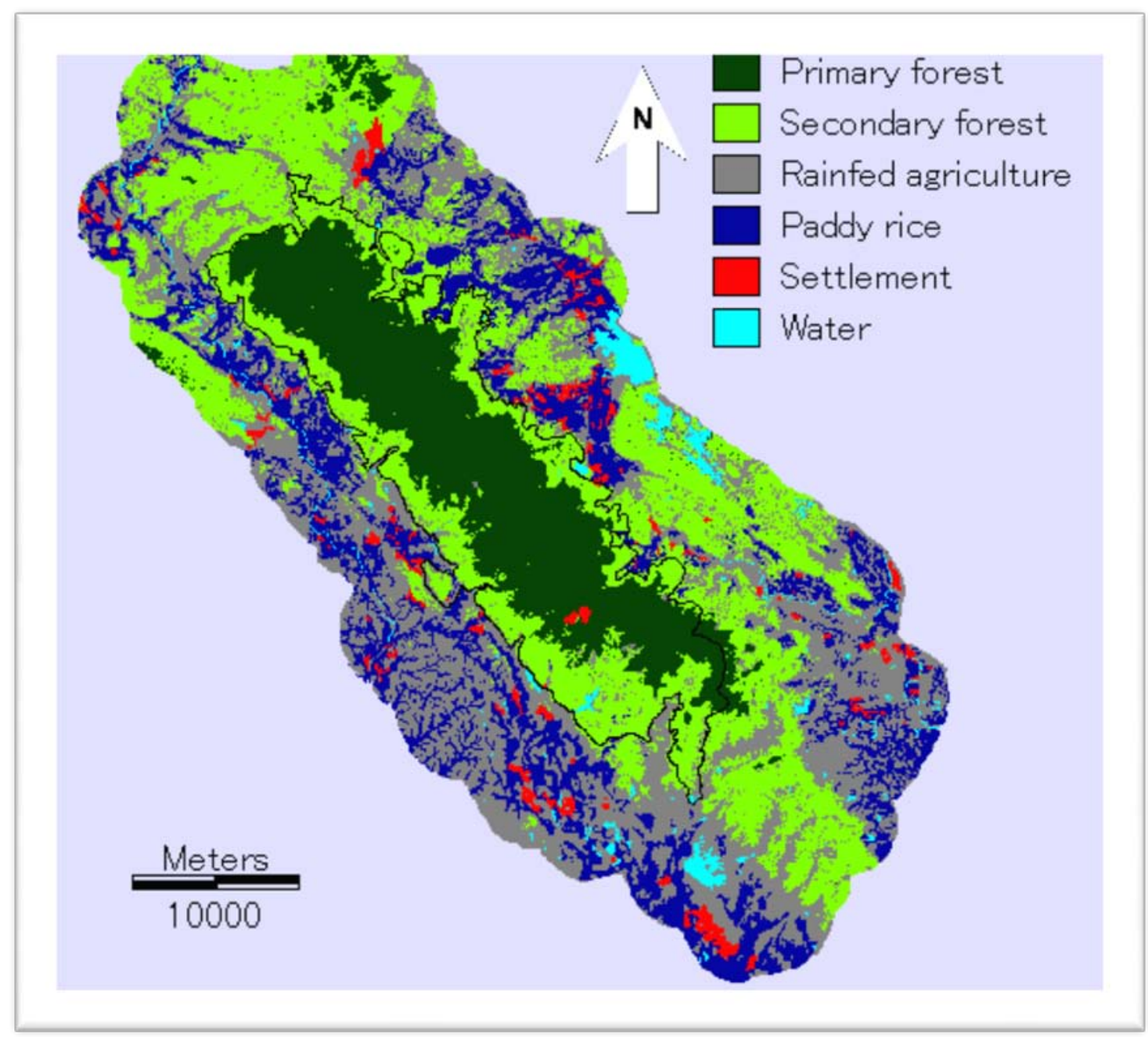

It is important to note that the farmers are not aware of formal land suitability assessment methods, but they trust their own experience regarding land suitability. The farmers have a profound knowledge of their lands and classify the suitability of the land according to crop yield. Crop yield often correlates with biophysical factors of the soil, such as terrain, fertility, and water availability. In the study, the 
factors selected based on the opinions of the experts cover the farmers' perception; therefore, the assessment spatially matches with the majority of existing cropland.

\section{Discussion}

In general, developing countries have adopted the North American approach to management of the PAs. This approach only emphasizes nature conservation [28], but the livelihoods of local populations in nearby PAs have often been ignored [29]. The recognition of PAs as part of a broader socio-economic system [3] led to the concept of protected area-buffer zone land-use management. The maintenance of the local communities' livelihoods and conservation has been challenging the TDNP managers. It argues that sustainable land use may not be achieved in isolation because agricultural expansion and poverty are interrelated. Poverty is a primary cause of cultivation of large areas of sloping lands in the region, which is exacerbating land degradation. Therefore, land use policy and other development policies should be combined to improve the living standards of the poor; and thereby may reduce overexploitation of land resource and land degradation in the area.

An LSA is a preliminary stage for assessing whether land is likely to be practical and successful for sustainable development of the intended goals. In many cases, cropland has been promoted in areas that are unsuitable in terms of soil conditions. Due to increasing population pressures, agricultural expansion has been increasing in the TDNP region without consideration of the site suitability. To ensure sustainable land uses, there is a great need to allocate farming activities to suitable locations to prevent undesirable effects on biodiversity conservation efforts as well as land degradation in the region. TDNP and its buffer zone management documents were reviewed. The TDNP-buffer zone management emphasizes the integrity of the buffer zone and the TDNP, particularly regarding sustainable land uses in the buffer zone [15,17]. Buffer zone land-use management affects the protected area because the environmental quality of the buffer zone is critical to maintaining the ecological functions of the protected area [30]. In the TDNP region, land is an important resource for the enhancement of the living standard of local people near the PA. Land-use management of the buffer zone is facing the issue of balancing agricultural development and forest conservation. The approach and results presented in this study may support land-use management decisions towards a more sustainable PA system. It is assumed that different crop farming strategies should be practiced according to the varying degree of suitability; therefore, we recommend farming strategies for four zones according to the four levels of suitability shown in the land suitability map. Sustainable land-use projects supported by local and central governments should be invested in accordance with each of the zones. We believe that if such farming strategies are introduced according to these zones, they can prevent further deforestation and improve the appropriate use of land in the buffer zone.

First, for the most suitable zone, most of the zone has been used for rain-fed agriculture and paddy rice. This zone is distributed over the lowlands around the region (Figure 6). Every household can improve their income if the productivity of crops is improved from this zone. Therefore, a greater intensification of crops, such as paddy rice and maize, should be encouraged to enhance agricultural productivity in this zone, and thus, the production pressure on the marginally suitable zone can be reduced. This strategy has been successfully implemented, and it can be arguably explained as one of main causes for the increase in reforestation across Vietnam [31]. However, some of the secondary 
forest (1,339 ha) was evaluated to be highly suitable for cropland. These areas may be converted into cropland due to population pressures. In such situations, agro-forestry systems (AFS) should be practiced. AFS, the combined use of crops and trees on the same area of land, plays ecological, social, and economic roles [32]. For example, AFS can reduce soil erosion and the loss of soil nutrients, improve landscape diversity [33] and generate income for farmers. If AFS is practiced, a state subsidy for farmers may be needed in the long-term because this system often generates less income [15]. The subsidy can be understood as a means of compensation for farmers because they contribute to conservation efforts through more sustainable land use. The state subsidy should become a common policy for all protected areas across the country.

Second, for the moderately suitable zone, the majority of the zone has also been used for rain-fed agriculture and paddy rice. The diversification of crops and AFS may be a strategic option for the moderately suitable zone. The current least productive rain-fed agriculture should be converted into perennial crops, such as tea and fruit trees. These crops can increase land coverage and thus can be a more sustainable land-use type. However, a large portion of the secondary forest was assessed to be moderately suitable for cropland (Table 6). This portion can be potentially converted into cropland. The conversion of this portion into cropland should be restricted because it is spread over steep land that is highly vulnerable to soil erosion. Third, the marginally suitable and unsuitable zones should be strictly restricted to agricultural activities because most of these zones are the primary forest and the secondary forest. This restriction may link with the reduced welfare of the population. This requires state support for people heavily dependent on natural resources for their well-being. For example, non-farming jobs, such as handy crafts and ecotourism, can be alternatives or additional livelihoods that should be considered.

Some concrete measures should be considered for the implementation of agricultural intensification and AFSs, which prevent further deforestation and land degradation in the region. It is argued that intensification and AFSs are the key activities that enhance sustainable land use. Crop intensification systems may minimize expansion of new cultivation area into the forest because they expect to increase agricultural productivity in the region. Measures for the intensification systems should aim to enhance the local farmer's capacity via support projects. These projects should focus on the irrigation system, hybrid crop varieties, soil nutrient management, and integrated pest management. Improvement of the irrigation system can trigger an increase in maize area in the winter season, and thus agricultural productivity is substantially increased. Introduction of hybrid crop varieties in combination with soil nutrient management and integrated pest management can be implemented through technical training courses for the farmers. For the sloping lands, there is a definite need of combining forestry, crop, and animal husbandry on individual farms to replace mono-cropping. These combinations can have a synergistic effect on the productivity of the land and its resilience to degradation. The AFS should be demonstrated in the first step of introduction because these systems are not commonly practiced by the farmers in the region. The purpose of the demonstration is to help the local farmers to acquire knowledge of how to efficiently utilize their sloping land. Both technical and financial supports are very important for the implementation of the systems. Agricultural extension workers should be employed for each commune or village because timely technical supports for the farmers are needed. 
It should be noted that the land suitability map is intended to guide regional land use decisions. From the TDNP manager perspective, it can be used for a decision making process that allocates land to the uses that provide the greatest benefits of conservation of biodiversity and other ecosystem services. However, on a local scale, the farmers may not adopt the land use plan because the farmers' land use decisions are affected by several factors: mainly their economic conditions. Most farmers avoid bank loans if they have other investment choices. They commonly adopt low investment alternatives because self-subsistence farmers tend to adopt short-term objectives in nature, and they are likely to have a low priority for long-term benefits. This low investment involves enlargement of cultivation area, which contradicts conservation or maintenance of ecosystem services. The managers are confronted with the decisions to be made. This may require a negotiation process between the managers and the farmers. Once a consensus has been gained through negotiation, the practicality of the plan's implementation can be achieved.

Though the GIS-MCE approach provides an effective framework for land evaluation, the selection of assessment factors and the identification of a suitable range for each factor have a direct influence on the results. In this study, the factors were selected based on the local experts; therefore, they represent a considerable share of the factors relevant to the suitability of growing areas in the region. Moreover, the FMF approach was used to standardize the factors. The FMF approach is useful because it is good at dealing with land-use suitability classes that do not have clearly defined boundaries [34]. Therefore, the suitability map represents a more accurate result. In particular, the integration of spatial databases and expert knowledge significantly enhances the decision-making capacity when undertaking land suitability evaluations. Moreover, the approach highlights the participatory decision-making process [35]. Therefore, it can minimize and solve conflicts among competing interests in the area of protected area-buffer zone land-use management.

The GIS-MCE approach has been widely applied in land suitability analysis [12]; however, the application of the method in protected area-buffer zone management is relatively new in Vietnam. GIS-MCE has shown the capacity, as a tool for decision support, in making choices among land-use alternatives. The MCE of soil, topography, and accessibility factors was exemplified to be useful for delineating areas suitable for cropland in the TDNP region. In particular, the involvement of local experts was vital to obtaining consistent results. The experts played key roles in the selection of the evaluation factors and in the determination of the factor weights. The remote sensing data offered land-use information that was crucial to examining the spatial matching between the potential suitability areas and the current land-use patterns. This information helped to identify whether the land has been used optimally, and whether future land uses can be modified for the region. The application of this paper can be useful for the managers and planners who manage protected area-buffer zone resources.

This investigation offered valuable information for the TDNP managers. The results can be used to prioritize land use management projects funded by local and central governments and other non-governmental organizations. The study shows that GIS databases of different formats and sources can be efficiently integrated to establish a land suitability assessment for cropland. The methodology is useful for identifying priority areas for crop farming, and thus, it contributes to improving the efficiency of conservation and of sustainable land management. The approach can be also handy for land use managers working in other Vietnam's protected areas that have similar conditions to the 
TDNP region. The land suitability information produced in the recent research is valuable. However, land use decisions are based on not only such information but also on other assessments, such as economic analysis of land uses and environmental impact assessments. Therefore, we recommend that future studies should consider these assessments to offer decision makers a comprehensive basis on which to orient their feasible strategy, and to make a sound decision towards a more sustainable TDNP.

\section{Acknowledgements}

The authors are grateful to Do Dinh Tien, the director of the TDNP office for providing spatial databases, the field trip arrangement and the survey. We own a debt of gratitude to the experts and officials of the TDNP for sharing their knowledge, experiences and opinions during the study period. We wish to thank to two anonymous reviewers for their constructive comments and suggestions that helped us to improve the manuscript substantially. Special thanks also go to Rajesh Bahadur Thapa for his kind assistance in preparing the manuscript.

\section{References and Notes}

1. Global Forest Resources Assessment: Progress toward Sustainable Forest Management; FAO: Rome, Italy, 2005; Available online: http://www.fao.org/DOCREP/008/a0400e/a0400e00.htm (accessed on 25 September 2008).

2. Guidelines for Protected Area Management Categories; International Union for the Conservation of Nature (IUCN): Gland, Switzerland, 1994.

3. McNeely, J.A. Parks for Life: Report of the IVth World Congress on National Parks and Protected Areas; IUCN: Gland, Switzerland, 1993.

4. Overview-What is a Protected Area? WCPA (World Commission on Protected Areas): Townsville, QLD, Australia, 2010; Available online: http://www.iucn.org/about/union/ commissions/wcpa/wcpa overview/ (accessed on 3 April 2010).

5. Phuong, N.N.; Dembner S.A. Improving the Lifestyles of People in Protected Areas of Vietnam; FAO: Rome, Italy, 1994; Available online: http://www.fao.org/docrep/v2900e/v2900e00. htm\#Contents (accessed on 2 April 2010).

6. Vietnam National Report on Protected Areas and Development; International Centre for Environmental Management (ICEM): Indooroopilly, QLD, Australia, 2003; pp. 19-47.

7. van Ranst, E.; Tang, H.; Groenemans, R.; Sinthurahat, S. Application of fuzzy logic to land suitability for rubber production in peninsular Thailand. Geoderma 1996, 70, 1-19.

8. Collins, M.G.; Steiner, F.R.; Rushman, M.J. Land-use suitability analysis in the United States: Historical development and promising technological achievements. Environ. Manage. 2001, 28, 611-621.

9. Stainer, F. Landscape planning: A method applied to a growth management example. Environ. Manage. 1991, 15, 519-529.

10. Sui, D.Z. Integrating neural networks with GIS for spatial decision making. Oper. Geogr. 1993, 11, 13-20.

11. Pereira, J.M.C.; Duckstein, L. A. multiple criteria decision-making approach to GIS-based land suitability evaluation. Int. J. Geog. Inf. Syst. 1993, 7, 407-424. 
12. Malcewski, J. GIS-based multicriteria decision analysis: A survey of the literature. Int. J. Geog. Inf. Syst. 2006, 20, 703-726.

13. Cover, S.J. Integrating multi-criteria evaluation with geographical information systems. Int. J. Geog. Inf. Syst. 1991, 5, 321-339.

14. Malcewski, J. Spatial multicriteria decision analysis. In Spatial Multicriteria Decision Making and Analysis: A Geographical Information Sciences Approach; Ashgate Publishing: Aldershot, UK, 1999; pp.101-269.

15. Khang, N.D.; Hoe, H.; Duc, H.D.; Thin, N.N.; Tien, D.D.; Lanh, V.L.; Huyen, T.H. Tam Dao National Park; Agricultural Publishing House: Hanoi, Vietnam, 2007; pp. 9-56 (in Vietnamese).

16. Ghazoul, J. Frontier Vietnam Environmental Research Report 1-Tam Dao Nature Reserve: Results of a Biological Survey; Ministry of Agriculture and Rural Development: Hanoi, Vietnam, 1994.

17. Tam Dao National Park and Buffer Zone Management Project (TDMP). Rural Household Economics Baseline Survey 2005; Centre of Services, Eco-tourism \& Environmental Education: Tam Dao, Vienam, 2005; Available online: http://tamdaonp.com.vn/ (accessed on 2 March 2010).

18. Eastman, J.R. IDRISI Taiga, Guide to GIS and Remote Processing; Clark University: Worcester, MA, USA, 2009; pp. 234-256.

19. McBratney, A.B.; Odeh, I.O.A. Application of fuzzy sets in soil science: Fuzzy logic, fuzzy measurements and fuzzy decisions. Geoderma 1997, 77, 85-113.

20. Ahamed, T.R.N.; Rao, K.G.; Murthy, J.S.A. GIS-based fuzzy membership model for cropland suitability analysis. Agr. Syst. 2000, 63, 75-95.

21. Liu, Y.S.; Wang, J.Y.; Guo, L.Y. GIS-based assessment of land suitability for optimal allocation in the Qinling Mountains, China. Pedosphere 2006, 16, 579-586.

22. Quan, B.; Zhu, H.J.; Chen, S.L.; Romkens, M.J.M.; Li, B.C. Land suitability assessment and land use change in Fujian province, China. Pedosphere 2007, 17, 493-504.

23. Wang, X.; Lu, C.; Fang, J.; Shen, Y. Implications for development of grain-for-green policy based on cropland suitability evaluation in desertification-affected north China. Land Use Policy 2007, 24, 417-424.

24. Saaty, T.L. The Analytic Hierarchy Process; McGraw-Hill: New York, NY, USA, 1980.

25. Saaty, T.L. The Analytic Hierarchy Process: Planning, Priority Setting, Resource Allocation; RWS publications: Pittsburgh, PA, USA, 1990.

26. Eastman, J.R.; Jin, W.; Kyem, P.A.K.; Toledano, J. Raster procedures for multi criteria/multi objective decision. Photogramm. Eng. Remote Sensing 1995, 61, 539-547.

27. A Framework for Land Evaluation; soils bulletin No. 32; Food and Agriculture Organization of the United Nations (FAO): Rome, Italy, 1976.

28. Colchester, M. Salvaging nature: Indigenous peoples and protected areas. Social Change and Conservation: Environmental Politics and Impacts of National Parks and Protected Areas; Ghimire, K.B., Pimbert, M.P., Eds.; Earthscan: London, UK, 1997; pp. 97-130.

29. Pimbert, M.P.; Pretty, J.N. Parks, peoples and professionals: Putting participation into protected area management. In Social Change and Conservation: Environmental Politics and Impacts of 
National Parks and Protected Areas; Ghimire, K.B., Pimbert, M.P., Eds.; Earthscan: London, UK, 1997; pp. 297-330.

30. Bridle, J.R.; Pedro, P.M.; Butlin, R.K. Habitat fragmentation and biodiversity: Testing for the evolutionary effects of refugia. Evolution 2004, 58, 1394-1396.

31. Meyfroidt, P.; Lambin, F.E. The causes of the reforestation in Vietnam. Land Use Policy 2008, 25, 182-197.

32. Jianbo, L. Energy balance and economic benefits of two agroforestry systems in northern and southern China. Agri. Ecosyst. Environ. 2006, 116, 255-262.

33. Palma, J.H.N.; Graves, A.R.; Burgess, P.J.; Keesman, K.J.; van Keulen, H.; Mayus, M.; Reisner, Y.; Herzog, F. Methodological approach for the assessment of environmental effects of agroforestry at the landscape scale. Ecol. Eng. 2007, 29, 450-462.

34. Groenemans, R.; Ranst, E.V.; Kerre, E. Fuzzy relational calculus in land evaluation. Geoderma 1997, 77, 283-298.

35. Eastman, J.R.; Jin, W.; Kyem, P.A.K.; Toledano, F. Participatory procedures for multi-criteria evaluation in GIS. In Proceedings of Chinese Professionals in GIS 92; NCGIA: Buffalo, NY, USA, 1992; pp. 281-288.

(C) 2010 by the authors; licensee MDPI, Basel, Switzerland. This article is an Open Access article distributed under the terms and conditions of the Creative Commons Attribution license (http://creativecommons.org/licenses/by/3.0/). 